\title{
Microbiological and host features associated with corynebacteriosis in cancer patients: a five-year study
}

\author{
CAS Martins ${ }^{1,3}$, LMD Faria', MC Souza ${ }^{3}$, TCF Camello ${ }^{3}$, E Velasco' ${ }^{1}$, R Hirata Jr³, \\ LCS Thuler², AL Mattos-Guaraldi ${ }^{3 /+}$
}

${ }^{1}$ Instituto Nacional do Câncer, Ministério da Saúde, Rio de Janeiro, RJ, Brasil ²Universidade Federal do Rio de Janeiro, Rio de Janeiro, RJ, Brasil ${ }^{3}$ Disciplina de Microbiologia e Imunologia, Faculdade de Ciências Médicas, Universidade do Estado do Rio de Janeiro, Av. 28 de Setembro 87 fundos, 3o andar, 20551-030 Rio de Janeiro, RJ, Brasil

During a five-year period, 932 clinical isolates from cancer patients treated in a Brazilian reference centre were identified as corynebacteria; $86 \%$ of the cultures came from patients who had been clinically and microbiologically classified as infected and $77.1 \%$ of these patients had been hospitalised (71.1\% from surgical wards). The adult solid tumour was the most common underlying malignant disease (66.7\%). The univariate and multivariate analyses showed that hospitalised patients had a six-fold greater risk $(O R=5.5,95 \% C I=1.15-26.30 p=0.033)$ related to 30-day mortality. The predominant species were Corynebacterium amycolatum (44.7\%), Corynebacterium minutissimum (18.3\%) and Corynebacterium pseudodiphtheriticum (8.5\%). The upper urinary tracts, surgical wounds, lower respiratory tracts, ulcerated tumours and indwelling venous catheters were the most frequent sources of $\mathrm{C}$. amycolatum strains. Corynebacterium jeikeium infection occurred primarily in neutropenic patients who have used venous catheters, while infection caused by $\mathrm{C}$. amycolatum and other species emerged mainly in patients with solid tumours.

Key words: Corynebacterium amycolatum - Corynebacterium infection - cancer

Corynebacterium species have recently been recognised as important pathogens that infect immunocompromised patients. Despite the increase in the number of reports of severe infection caused by non-diphtheria corynebacteria, these organisms are still frequently dismissed as contaminants. Corynebacterium spp have been cited with an increased frequency as pathogens of nosocomial infections associated with septicaemias, endocarditis, infections of surgical wounds, prostheses and infections related to the central venous catheter. Geographical variations in the frequency of isolated species and variations in the natural and acquired antimicrobial resistance have been described (Osterwalder et al. 1986, Rozdzinski et al. 1991, van der Lelie et al. 1995).

Recent advances in Corynebacterium identification have shown that the genus exhibits considerable taxonomic complexity and that the phenotypic markers used in the past for its identification can be ambiguous (Barreau et al. 1993, Brandenburg et al. 1996, Oteo et al. 2001, Camello et al. 2003, Meyer \& Reboli 2005, Otsuka et al. 2006). When these infections are linked to multiresistant species, they are difficult to treat (Bodey 1995, Funke et al. 1996, Camello et al. 2003, Funke \& Bernard 2003). Multiple resistance to antimicrobial agents has been described among some species (Lagrou et al. 1998,

Financial support: INCA, FAPERJ, CNPq, CAPES, SR-2/UERJ, PRONEX

+ Corresponding author: guaraldi@uerj.br

Received 15 May 2009

Accepted 20 August 2009
Zalas et al. 2004); for example, mutations in the gyrase genes are determinants of the resistance to quinolones in Corynebacterium striatum and Corynebacterium amycolatum strains (Sierra et al. 2005).

In Rio de Janeiro, Brazil, recent studies conducted at a teaching hospital showed that $68 \%$ of the clinical isolates of corynebacteria species corresponded to Corynebacterium pseudodiphtheriticum, C. amycolatum, Corynebacterium propinquum and Corynebacterium minutissimum. The urinary tract and the venous access were the sites most commonly affected. In the blood and the respiratory tract, there was a predominance of C. pseudodiphtheriticum and C. propinquum, while Corynebacterium xerosis and C. amycolatum were the most commonly observed species in central venous catheters. C. propinquum and C. minutissimum were the most frequently observed species in surgical wounds. Data indicated the occurrence of multi-resistant phenotypes and the possibility of severe infections due to $C$. pseudodiphtheriticum, a pathogen usually overlooked in emerging countries (Camello et al. 2003, 2009).

Infection has been recognised as one of the major obstacles to the successful management of patients with malignant diseases. Few studies have described non-diphtheria corynebacteria species as emerging pathogens in patients with solid tumours, with the exception of those that highlighted the importance of Corynebacterium jeikeium (Rozdzinski et al. 1991, van der Lelie et al. 1995). Vancomycin has been demonstrated to be the primary treatment option for $C$. jeikeium. The choice of using glycopeptides to empirically treat patients with neutropenic fever and persistent fever has been criticised since the advent of the vancomycin-resistant Enterococcus and the heterogeneous vancomycin-intermediate Staphylococcus aureus (Furtado et al. 2006). The new options for therapy 
are also not completely safe for the treatment of gram positive life-threatening infections partially due to the emergence of microbial resistance (Boucher et al. 2000, Dobbs et al. 2006, Schoen et al. 2009).

The aim of this descriptive study was to assess the microbiological and clinical aspects as well as factors related to 30 -day mortality in cancer patients with corynebacteriosis.

\section{PATIENTS, MATERIALS AND METHODS}

Study setting - In this descriptive study, we retrospectively reviewed clinical and microbiological data over a five-year period (from January 2000-December 2004). The patient information originated from one of the units (Cancer Hospital I with 200 beds, Cancer Hospital II with 90 beds and Cancer Hospital III with 60 beds) of the National Cancer Institute (INCA) in Rio de Janeiro, Brazil.

The analysis included bacteriological data from 88,541 cultures and 1,100 irregular gram-positive rods isolated from cancer patients. The operational units included the Laboratory of Microbiology and the Hospital Infection Control Committee (HICC) at the INCA and the Laboratory of Diphtheria and Corynebacteria, State University of Rio de Janeiro (UERJ), Brazil.

During the period of the study, there were no changes in the technical team who processed the material for bacteriological cultures or in the medical team who assisted the patients.

Ethics - This paper was submitted and approved by the Ethical Research Committee at INCA (CEP 008/06) and complies with the Brazilian Government's Ethical Guidelines for research involving human beings (resolution of the National Health Council/Ministry of Health).

Diagnostic measures - The study analysed the clinical characteristics of 315 patients with Corynebacterium isolates who had malignant diseases or underwent bone marrow transplantation in the last two years of the study. Data assessment was performed on the basis of a medical records review of patients.

The hospitalised patients were monitored by at least one member of the HICC as a part of the antimicrobial vigilance routine through daily microbiology laboratory charts. Ambulatory patients were identified by the dressing nurses committee, catheter ambulatory (both for children and adults) and bacteriological charts.

In addition to the physicians' experiences of treating patients with cancer in INCA, the diagnosis of bacterial infection was staged according to the Centers for Disease Control and Prevention (CDC) classification (CDC 1992).

The patients with positive cultures were interpreted as infected when these cultures were derived from a normally sterile site associated with a febrile illness. Alternatively, patients with positive cultures were interpreted as infected when a Corynebacterium spp was isolated from two or more non-sterile sites in which there was a suspicion of infection and the physician considered it clinically significant to immediately start a specific antimicrobial therapy. A positive urinary culture was considered as significant in the presence of local (dysuria, polyuria) or systemic signs of infection; pyuria was only required in non-neutropenic patients. Tracheal secretions in intubated patients, sputum or tracheal aspirations in non-intubated patients were considered as positive if they were associated with clinical or radiological signs that indicated an infection. Protected sampling was not performed in bronchoscopy (Garner et al. 1988, Hughes et al. 1996, Berghmans et al. 2003).

Bacterial strains and identification - We retrospectively reviewed 932 strains identified as Corynebacterium spp that were recovered from representative clinical sites of cancer patients with signs and symptoms of bacterial infection. Corynebacterium-like colonies were selected for further identification when they were grown in any quantity from normally sterile body fluid or when they were isolated in significant numbers or in pure culture from other specimens obtained at clinical sites in which infection was suspected (Funke \& Bernard 2003). All clinical samples yielding more than three organisms were regarded as contaminated and discarded (Thomson 2007).

The Maki's semi-quantitative method was used to distinguish infection ( $>15$ colonies) from contamination of catheter-tips (Maki et al. 1977). For quantitative BAL fluid cultures, a colony count $>10^{3}$ colony-forming units (CFU) $\mathrm{mL}^{-1}$ of potential pathogens was considered positive. Isolation of two or three species of microorganisms was regarded as a polymicrobial infection for catheter tips and the lower respiratory tract, respectively. Microorganisms were identified from the urine cultures in cystine lactose electrolytes deficient agar (CLED; Merck, Darmstadt, Germany) and were considered to be potential pathogens when the growth was $>10^{4} \mathrm{CFU} \mathrm{mL}^{-1}$ as the only isolate or $>10^{5} \mathrm{CFU} \mathrm{mL}^{-1}$ as the predominant isolate; $>10^{3} \mathrm{CFU} \mathrm{mL}^{-1}$, in cases of nephropathies, was also considered a potential pathogen. Blood cultures were always obtained in pairs, wherein at least one of the samples was collected through the central venous catheter, if present. Blood specimens were inoculated in Bactec Plus anaerobic/aerobic vials and processed in a Bactec 9240 continuous-monitoring system (BectonDickinson Microbiology System, Cockeysville, MD, USA). Other clinical specimens were inoculated onto a Columbia agar base with the addition of 5\% sheep's blood and incubated at $37^{\circ} \mathrm{C}$ in $3-5 \% \mathrm{CO}_{2}$ atmosphere and monitored for $72 \mathrm{~h}$.

In addition to Gram staining, colonial morphology, pigmentation and haemolysis, Corynebacterium-like colonies were characterised using the API-Coryne System (BioMérrieux, Lyon, France) (Freney et al. 1991). Microorganisms were also submitted to the following conventional biochemical assays: catalase, pyrazinamidase, lypophilic activities, motility, nitrate reduction, hydrolysis of urea and esculin, acidification of glucose, maltose, sucrose, mannitol and xylose, as well as oxidation-fermentation and CAMP reaction tests (Camello et al. 2003, Funke \& Bernard 2003).

Susceptibility testing - Antimicrobial susceptibility testing was performed by the Kirby Bauer's disk diffusion method, using an inoculum of $0.5 \mathrm{McF}$ arland stan- 
dard (150 x $10^{6} \mathrm{CFU} \mathrm{mL}^{-1}$ by direct colonial suspension), adjusted for optical density at $\lambda=550 \mathrm{~nm}$ (Vitek colorimeter Durham, NC, USA). The plates were incubated at $35^{\circ} \mathrm{C}$ in ambient air for $24 \mathrm{~h}$ and reconfirmed at $48 \mathrm{~h}$ in a cation-adjusted Mueller-Hinton Agar with the addition of 5\% sheep's blood (Funke et al. 1997). As there is not yet a defined standard by the Clinical and Laboratory Standards Institute for interpreting the results of disk diffusion tests (CLSI 2007), we used the breakpoint for penicillin suggested for Staphylococcus.

For the other antimicrobial agents, we used the breakpoints for other microorganisms but not Haemophilus spp or Neisseria gonorrhoeae, which had been validated by previous studies (Martinez-Martinez et al. 1995, Weiss et al. 1996, Zinkernagel et al. 1996, Funke et al. 1997).

The intermediate results were included as resistant. Microorganisms were tested against 15 antimicrobial agents, according to the clinical criteria for empirical therapy in patients with underlying malignancy and infection. The in vitro antimicrobial susceptibility test associated with the analysis of clinical relevance used the interpretation criteria suggested by the Sanford Guide (Gilbert et al. 2006): (+) usually clinically effective or $>60 \%$ susceptible, $( \pm)$ clinical trials lacking or $30-60 \%$ susceptible and $(0)$ not clinically effective or $<30 \%$ susceptible.

Statistical analysis - The variables were compared using a Pearson Chi square or Fisher exact test. For statistical significance, the value was established at $p$ $<0.05$. A logistic regression model was developed to identify the variables independently associated with the 30 -day mortality. This model included every variable that showed a statistically significant association $(\mathrm{p}<$ 0.05 ) in the univariate analysis. The softwares used for the statistical analysis were Epi-Info 2000 for Windows, version 3.3.2 and SPSS, version 14.

\section{RESULTS}

During a five-year period (from January 2000-December 2004), the clinical microbiology laboratory at INCA conducted 88,541 cultures, of which 25,173 (28.4\%) were positive $(n=36,199)$. Gram-positive rods represented $1,436(4 \%)$ of the clinical isolates. The genus Corynebacterium corresponded with $932(84.7 \%)$ of the total $(1,100$ strains) number of irregular gram-positive rods (Table I).

The Corynebacterium species isolated from cancer patients presenting signs and symptoms of infection are displayed in Table II. Most of the isolates (44.7\%) were recognised as C. amycolatum, followed by $C$. minutissimum (18.3\%) and C. pseudodiphtheriticum (8.5\%). C. jeikeium was the sixth in frequency among the isolates $(4.7 \%)$. The species Corynebacterium ulcerans and Corynebacterium pseudotuberculosis, which are usually associated with zoonoses, were absent or observed in a very low incidence in our population, respectively.

Taking into account the retrospective analysis of our study from 2000-2004, the isolation of C. amycolatum/ xerosis increased from $10.4-72.8 \%$. On the other hand, C. minutissimum decreased from $31.3-1.3 \%$; the percentage of Corynebacterium spp (unidentified species) went from $11.5-0 \%$ and C. striatum from $12.5-0.8 \%$. C. xerosis comprised 20 isolates in 2000 and six in 2001 and was absent from new isolates in the subsequent years.

During the second phase of the study (from January 2003-December 2004), 10 Corynebacterium species were observed in 425 clinical isolates obtained from 315 cancer patients. C. amycolatum was the most frequent clinical isolate, followed by C. pseudodiphtheriticum, C. jeikeium and C. minutissimum (Table III). When only bloodstream infections were considered, catheter-related infections were frequently observed. C. amycolatum was widely distributed in all topographies. The upper urinary tract, surgical wounds, lower respiratory tract, ulcerated tumours and indwelling venous catheters were the most

TABLE I

Strains of irregular gram-positive rods isolated from cancer patients between 2000-2004

\begin{tabular}{|c|c|c|c|c|c|c|}
\hline Genus & $\begin{array}{l}2000 \\
\mathrm{n}(\%)\end{array}$ & $\begin{array}{l}2001 \\
\mathrm{n}(\%)\end{array}$ & $\begin{array}{l}2002 \\
\mathrm{n}(\%)\end{array}$ & $\begin{array}{l}2003 \\
\mathrm{n}(\%)\end{array}$ & $\begin{array}{l}2004 \\
\mathrm{n}(\%)\end{array}$ & $\begin{array}{l}\text { Total } \\
\mathrm{n}(\%)\end{array}$ \\
\hline Corynebacterium & $192(80.3)$ & $158(83.2)$ & $152(78.8)$ & $191(88.0)$ & $239(91.6)$ & $932(84.7)$ \\
\hline Arcanobacterium & $16(6.7)$ & $4(2.1)$ & $8(4.1)$ & $8(3.7)$ & $5(1.9)$ & $41(3.7)$ \\
\hline Brevibacterium & $13(5.4)$ & $1(0.5)$ & $7(3.6)$ & $7(3.2)$ & $4(1.5)$ & $32(2.9)$ \\
\hline Actinomyces & $6(2.5)$ & $5(2.6)$ & $11(5.7)$ & $1(0.5)$ & $2(0.8)$ & $25(2.3)$ \\
\hline Aureobacterium & $2(0.8)$ & $10(5.3)$ & $8(4.1)$ & $1(0.5)$ & $2(0.8)$ & $23(2.1)$ \\
\hline Arthrobacter & - & $7(3.7)$ & $3(1.6)$ & $4(1.8)$ & $7(2.6)$ & $21(1.9)$ \\
\hline Leifsonia & $8(3.3)$ & $4(2.1)$ & $3(1.6)$ & $1(0.5)$ & $1(0.4)$ & $17(1.5)$ \\
\hline Propionibacterium & $1(0.5)$ & $1(0.5)$ & - & $3(1.3)$ & $1(0.4)$ & $6(0.6)$ \\
\hline Rothia & $1(0.5)$ & - & $1(0.5)$ & $1(0.5)$ & - & $3(0.3)$ \\
\hline Total & $239(100)$ & $190(100)$ & $193(100)$ & $217(100)$ & $261(100)$ & $1,100(100)$ \\
\hline
\end{tabular}

the strains identified as gram-positive regular rods [Lactobacillus (213), Bacillus (94), Rhodococcus (17), Listeria (9), Nocardia (2) and unidentified irregular gram-positive rods (1)] were not included in this study. 
TABLE II

Corynebacterium species isolated from cancer patients between 2000-2004

\begin{tabular}{|c|c|c|c|c|c|c|}
\hline Species & $\begin{array}{l}2000 \\
\mathrm{n}(\%)\end{array}$ & $\begin{array}{l}2001 \\
\mathrm{n}(\%)\end{array}$ & $\begin{array}{l}2002 \\
\mathrm{n}(\%)\end{array}$ & $\begin{array}{l}2003 \\
n(\%)\end{array}$ & $\begin{array}{l}2004 \\
\mathrm{n}(\%)\end{array}$ & $\begin{array}{l}\text { Total } \\
\mathrm{n}(\%)\end{array}$ \\
\hline Corynebacterium xerosis ${ }^{a} /$ Corynebacterium amycolatum & $20(10.4)$ & $40(25.3)$ & $65(42.8)$ & $118(61.8)$ & $174(72.8)$ & $417(44.7)$ \\
\hline Corynebacterium minutissimum & $60(31.3)$ & $54(34.2)$ & $37(24.3)$ & $17(8.9)$ & $3(1.3)$ & $171(18.3)$ \\
\hline Corynebacterium pseudodiphtheriticum & $9(4.7)$ & $10(6.3)$ & $7(4.6)$ & $16(8.5)$ & $37(15.5)$ & $79(8.5)$ \\
\hline Corynebacterium spp & $22(11.5)$ & $23(14.6)$ & $5(3.3)$ & $2(1.0)$ & - & $52(5.6)$ \\
\hline Corynebacterium striatum & $24(12.5)$ & $10(6.3)$ & $4(2.6)$ & $9(4.7)$ & $2(0.8)$ & $49(5.3)$ \\
\hline Corynebacterium jeikeium & $3(1.6)$ & $7(4.4)$ & $8(5.3)$ & $17(8.9)$ & $9(3.8)$ & $44(4.7)$ \\
\hline Corynebacterium propinquum & $5(2.6)$ & $5(3.2)$ & $9(5.9)$ & $3(1.6)$ & $6(2.5)$ & $28(3.0)$ \\
\hline Corynebacterium afermentans & $10(5.2)$ & $2(1.3)$ & $1(0.7)$ & $2(1.0)$ & $4(1.7)$ & $19(2.0)$ \\
\hline Corynebacterium urealyticum & $6(3.1)$ & $3(1.9)$ & $3(2.0)$ & - & $2(0.8)$ & $14(1.5)$ \\
\hline Corynebacterium Group G & $2(1.0)$ & $3(1.9)$ & $4(2.6)$ & $2(1.0)$ & $1(0.4)$ & $12(1.3)$ \\
\hline Corynebacterium diphtheriae & $4(2.1)$ & - & $4(2.6)$ & $2(1.0)$ & $1(0.4)$ & $11(1.2)$ \\
\hline Corynebacterium argentoratense & - & - & $2(1.3)$ & $3(1.6)$ & - & $5(0.5)$ \\
\hline Corynebacterium pseudotuberculosis & $1(0.5)$ & - & - & - & - & $1(0.1)$ \\
\hline Corynebacterium accolens & - & - & $1(0.7)$ & - & - & $1(0.1)$ \\
\hline Others $^{b}$ & $26(13.5)$ & $1(0.6)$ & $2(1.3)$ & - & - & $29(3.2)$ \\
\hline Total & $192(100)$ & $158(100)$ & $152(100)$ & $191(100)$ & $239(100)$ & $932(100)$ \\
\hline
\end{tabular}

a: 20 strains in 2000 and six in 2001 and no isolates in the following years; $b$ : includes species previously classified as Group I (1 isolate), Group A (2), Group B (12), Group F (7), Group F1 (3), Group GI (3) and Group G2 (1).

frequent sources of C. amycolatum strains. C. pseudodiphtheriticum strains were mainly isolated from the lower and upper respiratory tract and C. jeikeium from the intravenous sites and skin lesions. The antimicrobial spectra of microorganisms are exhibited in Table IV.

Clinical data of the 315 cancer patients with fever and/or other signs of infection were retrieved. The epidemiological characteristics, the topographies that were involved and the factors that predisposed cancer patients to corynebacteria infection are depicted in Table V. The findings were interpreted as infection in $86 \%$ of patients and specific treatments were initiated. Corynebacterium strains were observed as the only microorganism in $46 \%$ of the cultures. Bacterial colonisation was confirmed in 44 cases $(14 \%), 35$ of which originated in the respiratory tract ( 25 rhinosinusal, 3 lower respiratory and 7 upper respiratory), four cases were in central venous catheters (Maki method negative), two cases were in skin/tumours and one case was in a surgical wound; two cases were isolated from the digestive tract.

The main underlying malignant diseases were $66.7 \%$ adult solid tumours, followed by tumours of the central nervous system and paediatric solid tumours $(10.8 \%$ and $9.2 \%$, respectively). The patients from surgical wards (71.1\%) were previously submitted to head and neck (25.1\%), gynaecological (13.3\%) and abdominal-pelvic $(9.5 \%)$ surgeries. Surgical wound infections comprised $32.7 \%$ of these patients. The patients from clinical wards were from pediatrics (28.9\%), oncology (12.1\%) and haematology $(7.3 \%)$. The majority of patients had been hospitalised (77.1\%) and exposed to a hospital environment for a long term (median $=13$ days).
The clinical-epidemiological characteristics of 315 patients with 30-day mortality involved a uni and multivariate analysis of risk factors for corynebacteria-associated infection (Table IV).

\section{DISCUSSION}

Identification of non-diphtheria bacteria at the species level is often problematic. Recent advances in identification have shown that the genus exhibits considerable taxonomic complexity and the phenotypic markers that have been used in the past for its identification can be ambiguous. Even when sent to a reference laboratory, $30-50 \%$ of coryneform bacteria isolates cannot be reliably identified at the species level. Consequently, there is a low rate of identification from clinical isolates (Schiff et al. 2004).

Variations in the occurrence of Corynebacterium species during the course of the study were probably due to improvements in the taxonomy and laboratory diagnosis of the genus Corynebacterium. The substantial increase in the number of $C$. amycolatum isolates was partially due to the disappearance of $C$. xerosis and the significant reduction of $C$. striatum and $C$. minutissimum, which reflects the progress in the diagnosis of Corynebacterium species and consequently, the variability in antimicrobial sensitivity patterns. The former Corynebacterium CDC F-2 and CDC I-2 groups have been reclassified as $C$. amycolatum.

Due to imprecise diagnosis at the species level, data from the first three years (507 strains) were not included in the analysis of the bacteriological and clinical characteristics of cancer patients with corynebacteriosis. 


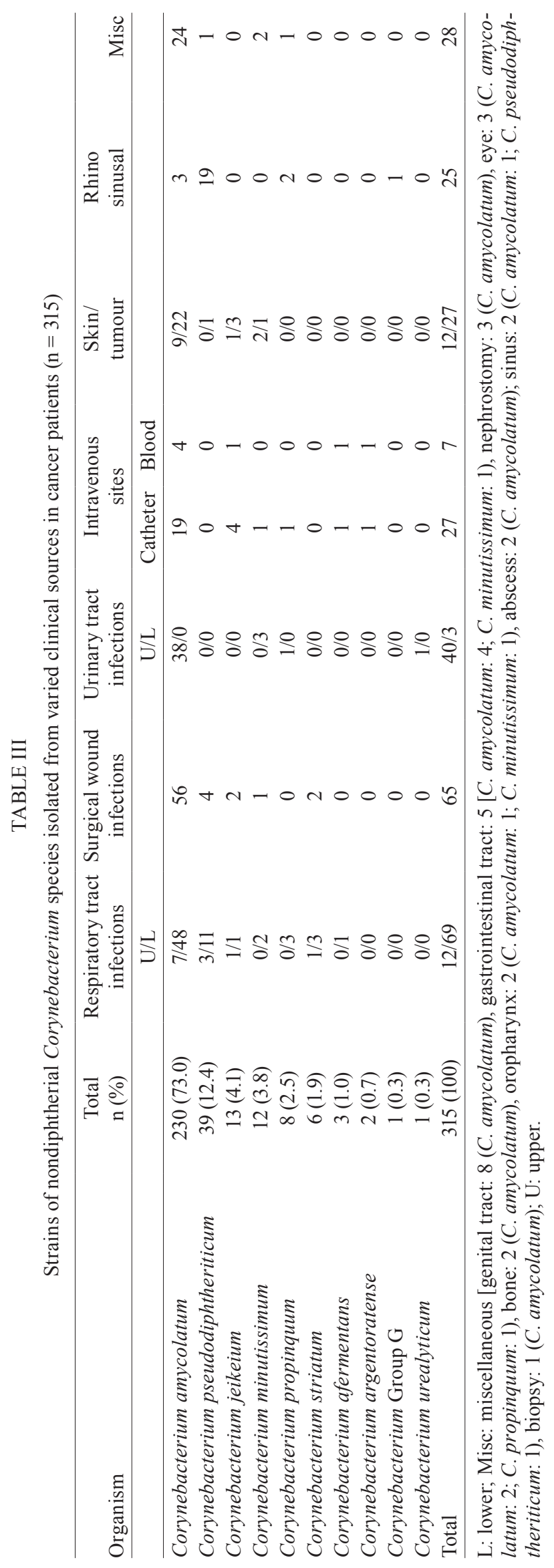

Many non-diphtheria corynebacteria-caused access infections can be effectively treated by antibiotics and local care. Susceptibility testing of corynebacteria is highly recommended to establish a specific therapy (CLSI 2007). Except for the unvarying activity of vancomycin against corynebacteria, the variability in resistance to other classes of antimicrobial agents emphasises the need for the continuous surveillance of their resistance patterns. Resistance to oxacillin was observed for all corynebacteria species isolated from cancer patients at INCA. The data emphasise the relevance of susceptibility testing of Corynebacterium isolates during the diagnosis and treatment of infections in cancer patients.

A growing number of reports have confirmed the importance of $C$. amycolatum in the aetiology of a variety of infectious processes. In the reviewed literature, many $C$. amycolatum clinical isolates were at first identified in different laboratories as C. xerosis (Funke et al. 1996) and C. minutissimum (Zinkernagel et al. 1996). After the mid-1990s, with the advent of the taxonomical characterisation of $C$. amycolatum, this species has been described as a causal agent of infections with high morbidity and mortality rates. Multi-resistant $C$. amycolatum strains were isolated from patients with septicaemia (Berner et al. 1997, de Miguel et al. 1999, Camello et al. 2003), septic arthritis after vascular transplants (Clarke et al. 1999), cardiac electrode implantation (Vaneechoutte et al. 1998), infections in vascular prostheses and open fractures (von Graevenitz et al. 1998), peritonitis in patients undergoing peritoneal dialysis (Chiu et al. 2005), infectious endocarditis accompanied by aorto-atrial fistula (Daniels et al. 2003), nosocomial endocarditis (Knox \& Holmes 2002) and septicaemia in leukemic patients (de Miguel et al. 1999). These reports drew attention to the clinical significance of $C$. amycolatum strains in different clinical materials (Esteban et al. 1999).

The clinical characteristics of the patients with favourable outcomes and documented corynebacteriosis could not be compared with those patients who died (controls). Due to the nature of the present research, which was a retrospective study, we could not investigate the pathogenicity of the isolates in relation to 30 day mortality in cancer patients. For the same reason, it was impossible to establish prognostic factors in these patients considering their descriptive characters. Another limitation of this study was the exclusion of isolates from 2000-2002 in the complete analysis due to major changes in taxonomical classification. Nevertheless, the sampling procedures adopted in this study allowed us to detect some patterns and characteristics of the population under investigation.

The univariate and multivariate analyses showed that hospitalised patients had a six-fold greater risk $(\mathrm{OR}=$ $5.5,95 \% \mathrm{CI}=1.15-26.30 \mathrm{p}=0.033$ ) related to 30 -day mortality. Also of statistical significance were patients bedridden for longer than $50 \%$ of the day with neoplastic disease in progress or diabetes mellitus.

The study revealed that corynebacteria are increasingly being recognised as a cause of infections in cancer patients. These organisms have been underreported, but 


\section{TABLE IV}

Comparison of antimicrobial spectra of Corynebacterium species (315 patients/425 strains)

Species (samples)

\begin{tabular}{|c|c|c|c|c|c|c|c|c|c|c|c|c|}
\hline 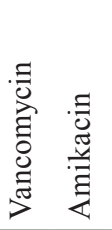 & 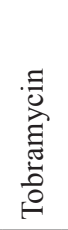 & 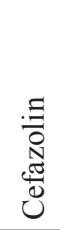 & 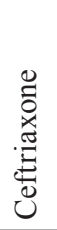 & 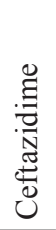 & 节 & 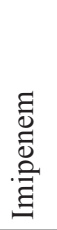 & 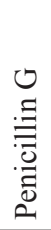 & 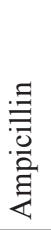 & 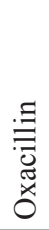 & 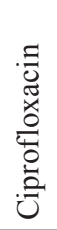 & $\begin{array}{l}\stackrel{\Xi}{0} \\
\tilde{\pi} \\
0 \\
0 \\
0\end{array}$ & 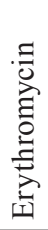 \\
\hline+ & + & + & + & 0 & + & + & + & + & 0 & \pm & \pm & \pm \\
\hline+ & + & + & + & + & + & + & + & + & + & + & + & \pm \\
\hline 0 & 0 & 0 & 0 & 0 & 0 & 0 & 0 & 0 & 0 & 0 & 0 & 0 \\
\hline+ & + & + & + & 0 & + & + & \pm & \pm & 0 & \pm & \pm & \pm \\
\hline+ & + & + & + & 0 & + & + & + & + & 0 & \pm & \pm & + \\
\hline+ & + & + & + & \pm & + & + & + & + & \pm & + & + & \pm \\
\hline+ & + & + & + & \pm & + & + & \pm & \pm & \pm & + & + & \pm \\
\hline+ & + & + & + & 0 & + & + & + & + & 0 & + & + & + \\
\hline+ & + & + & + & \pm & + & + & + & + & 0 & + & + & + \\
\hline \pm & \pm & \pm & \pm & \pm & \pm & \pm & \pm & \pm & \pm & + & + & 0 \\
\hline
\end{tabular}

Corynebacterium amycolatum (292)

Corynebacterium pseudodiphtheriticum (53)

Corynebacterium jeikeium (26)

Corynebacterium minutissimum (20)

Corynebacterium striatum (11)

Corynebacterium propinquum (9)

Corynebacterium afermentans (6)

Corynebacterium Group G (3)

Corynebacterium argentoratense (3)

Corynebacterium urealyticum (2)

+: > 60\%; $\pm:$ 30-60\%; 0: <30\% (\% sensitivity).

TABLE V

Risk factors to mortality related to Corynebacterium spp infection in 315 cancer patients

\begin{tabular}{|c|c|c|c|c|}
\hline Predictors & $\begin{array}{c}\text { Patients } \\
\text { who survived } \\
\mathrm{n}=271(\%)\end{array}$ & $\begin{array}{c}\text { Patients } \\
\text { who died } \\
\mathrm{n}=44(\%)\end{array}$ & OR $(95 \% \mathrm{CI})$ & $\mathrm{p}$ value \\
\hline $\begin{array}{ll} & <65 \text { years } \\
& \geq 65 \text { years }\end{array}$ & $\begin{array}{c}197(72.7) \\
74(27.3)\end{array}$ & $\begin{array}{l}29(65.9) \\
15(34.1)\end{array}$ & $1.38(0.66-2.85)$ & 0.354 \\
\hline Gender (female) & $154(56.8)$ & $18(40.9)$ & $0.52(0.27-1.00)$ & 0.049 \\
\hline Central venous catheter used & $31(11.4)$ & $7(15.9)$ & $1.46(0.60-3.56)$ & 0.398 \\
\hline Central venous catheter infection & $22(8.1)$ & $6(13.6)$ & $1.78(0.68-4.69)$ & $0.251^{a}$ \\
\hline Corynebacterium minutissimum & $7(2.6)$ & $5(11.4)$ & $4.83(1.46-15.98)$ & $0.016^{a}$ \\
\hline Hospitalized patients & $201(74.2)$ & $42(95.5)$ & $7.31(1.72-31.00)$ & 0.002 \\
\hline Infection (versus colonization) & $232(85.6)$ & $39(88.6)$ & $1.31(0.48-3.53)$ & 0.591 \\
\hline Diabetes mellitus (plasma glucose $>200 \mathrm{mg} / \mathrm{dL}$ ) & $19(7.0)$ & $8(18.2)$ & $2.94(1.20-7.22)$ & $0.036^{a}$ \\
\hline Renal insufficiency (creatinine $>2.0 \mathrm{mg} / \mathrm{dL}$ ) & $20(7.4)$ & $10(22.7)$ & $3.69(1.59-8.54)$ & $0.004^{a}$ \\
\hline Hematopoietic stem cell transplantation & $5(1.8)$ & $1(2.3)$ & $1.23(0.14-0.84)$ & $0.598^{a}$ \\
\hline Co-infection & $102(37.6)$ & $26(59.1)$ & $2.39(1.25-4.58)$ & 0.007 \\
\hline Undergo surgery & $156(57.6)$ & $16(36.4)$ & $0.42(0.21-0.81)$ & 0.009 \\
\hline Surgical wound infection & $63(23.2)$ & $2(4.5)$ & $0.15(0.03-0.66)$ & 0.004 \\
\hline COPD & $14(5.2)$ & $2(4.5)$ & $0.87(0.19-3.98)$ & $1.000^{a}$ \\
\hline Confined to bed more than $50 \%$ of waking hours & $42(15.5)$ & $20(45.5)$ & $4.54(2.30-8.95)$ & $<0.001$ \\
\hline Solid tumors & $240(88.6)$ & $34(77.3)$ & $0.43(0.19-0.97)$ & 0.039 \\
\hline Length of stay $>13$ days & $165(60.9)$ & $27(61.4)$ & $1.02(0.53-1.96)$ & 0.952 \\
\hline Neutropenia $(<1000 \mu \mathrm{L} /$ cells $)$ & $14(5.2)$ & $4(9.1)$ & $1.83(0.57-5.85)$ & $0.294^{a}$ \\
\hline Isolated in pure culture & $125(46.1)$ & $20(45.5)$ & $0.97(0.51-1.84)$ & 0.934 \\
\hline Isolated in association & $23(8.5)$ & $6(13.6)$ & $1.70(0.65-4.45)$ & $0.266^{a}$ \\
\hline Isolated in co-infection not related & $22(8.1)$ & $5(11.4)$ & $1.45(0.51-4.05)$ & $0.559^{a}$ \\
\hline Under nutrition (weight loss $>10 \%$ ) & $43(15.9)$ & $13(29.5)$ & $2.22(1.07-4.59)$ & 0.028 \\
\hline Body temperature $>38^{\circ} \mathrm{C}$ & $19(7.0)$ & $4(9.1)$ & $1.32(0.42-4.10)$ & $0.543^{a}$ \\
\hline Mucositis ( NCI scale > 3 ) & $4(1.5)$ & $0(0.0)$ & $0.85(0.82-0.89)$ & $1.000^{a}$ \\
\hline
\end{tabular}




\begin{tabular}{lcccc}
\hline & $\begin{array}{c}\text { Patients } \\
\text { who survived } \\
\mathrm{n}=271(\%)\end{array}$ & $\begin{array}{c}\text { Patients } \\
\text { who died } \\
\mathrm{n}=44(\%)\end{array}$ & OR (95\% CI) & $\mathrm{p}$ value \\
Predictors & $87(32.1)$ & $28(63.6)$ & $3.70(1.90-7.19)$ & $<0.001$ \\
\hline Karnofsky index $<70 \%$ & $27(10.0)$ & $3(6.8)$ & $0.66(0.19-2.28)$ & $0.781^{a}$ \\
Corticotherapy (prednisone $>40 \mathrm{mg} / \mathrm{day})$ & $18(6.6)$ & $10(22.7)$ & $4.13(1.76-9.69)$ & $0.002^{a}$ \\
Arterial hypotension (systolic $<90 \mathrm{~mm} / \mathrm{hg})$ & $2(0.7)$ & $1(2.3)$ & $3.12(0.27-35.24)$ & $0.364^{a}$ \\
Graft-versus-host disease & $33(12.2)$ & $8(18.2)$ & $1.60(0.68-3.74)$ & 0.272 \\
Isolated in persistent infection & $94(34.7)$ & $12(27.3)$ & $0.70(0.34-1.43)$ & 0.334 \\
Radiotherapy & $48(17.7)$ & $13(29.5)$ & $1.94(0.94-3.99)$ & 0.065 \\
Tracheotomy & $108(39.9)$ & $33(75.0)$ & $4.52(2.19-9.34)$ & $<0.001$ \\
Progressive disease & $76(28.0)$ & $13(29.5)$ & $1.07(0.53-2.16)$ & 0.837 \\
Chemotherapy & $58(22.1)$ & $13(30.2)$ & $1.52(0.74-3.11)$ & 0.244 \\
Others Corynebacterium growing in association & $5(1.8)$ & $0(0.0)$ & $0.85(0.82-0.89)$ & $1.000^{a}$ \\
Ascites & $1(0.4)$ & $1(2.3)$ & $6.27(0.38-102.27)$ & $0.260^{a}$ \\
Tumoral embolization & $11(4.1)$ & $2(4.5)$ & $1.12(0.24-5.25)$ & $0.700^{a}$ \\
Pulmonary thrombo-embolism & $14(5.2)$ & $3(6.8)$ & $1.34(0.37-4.87)$ & $0.716^{a}$ \\
Instrumentalization & & & &
\end{tabular}

a: Fisher exact test

\section{TABLE VI}

Multivariate analysis of independent risk factors for 30-day mortality

\begin{tabular}{|c|c|c|c|c|}
\hline \multirow{2}{*}{$\frac{\text { Variable }}{\text { Hospitalized patients }}$} & \multirow{2}{*}{$\frac{\mathrm{OR}}{5.500}$} & \multicolumn{2}{|c|}{$95 \% \mathrm{CI}$} & \multirow{2}{*}{$\frac{\mathrm{p} \text { value }}{0.033}$} \\
\hline & & 1.150 & 26.304 & \\
\hline Confined to bed more than $50 \%$ of waking hours & 3.621 & 1.173 & 11.179 & 0.025 \\
\hline Corynebacterium minutissimum & 3.560 & 0.681 & 18.625 & 0.133 \\
\hline Progressive disease & 3.167 & 1.346 & 7.453 & 0.008 \\
\hline Diabetes mellitus (plasma glucose $>200 \mathrm{mg} / \mathrm{dL}$ ) & 3.106 & 1.015 & 9.504 & 0.047 \\
\hline Renal insufficiency (creatinine $>2.0 \mathrm{mg} / \mathrm{dL}$ ) & 2.710 & 0.951 & 7.722 & 0.062 \\
\hline Arterial hypotension (systolic < 90 mm/hg) & 2.429 & 0.851 & 6.934 & 0.097 \\
\hline Undernutrition (weight loss $>10 \%$ ) & 1.842 & 0.710 & 4.779 & 0.209 \\
\hline Isolated in co-infection no related & 1.260 & 0.572 & 2.773 & 0.566 \\
\hline Solid tumors & 0.762 & 0.268 & 2.169 & 0.610 \\
\hline Gender (male) & 0.656 & 0.295 & 1.457 & 0.301 \\
\hline Undergo surgery & 0.441 & 0.192 & 1.012 & 0.053 \\
\hline Karnofsky $<70$ & 0.835 & 0.287 & 2.425 & 0.740 \\
\hline
\end{tabular}

they may account for approximately $4 \%$ of the cases of infection in patients presenting solid tumours. The data reflects a tendency towards infection or colonisation by Corynebacterium in cancer patients who have undergone surgical procedures and a long subsequent hospitalisation period. From the study data, we also emphasise the need for the rigorous identification of Corynebacterium species isolates from different sites, especially of invasive strains in patients with clinical conditions of persistent fever and no other attributable site of infection. C. jeikeium infection occurs primarily in neutropenic patients who have used venous catheters (Rozdzinski et al. 1991), while C. amycolatum infection appears mainly in patients with solid tumours.

\section{REFERENCES}

Barreau C, Bimet F, Kiredjian M, Rouillon N, Bizet C 1993. Comparative chemotaxonomic studies of mycolic acid-free coryneform bacteria of human origin. J Clin Microbiol 31: 2085-2090.

Berghmans T, Sculier JP, Klastersky J 2003. A prospective study of infections in lung cancer patients admitted to the hospital. Chest 124: $114-120$.

Berner R, Pelz K, Wilhelm C, Funke A, Leititis JU, Brandis M 1997. Fatal sepsis caused by Corynebacterium amycolatum in a premature infant. J Clin Microbiol 35: 1011-1012.

Bodey GP 1995. Emerging antimicrobial-resistant pathogens in the immunocompromised host. Curr Opin Infect Dis 8: 411-414.

Boucher HW, Wennersten CB, Eliopoulos GM 2000. In vitro activi- 
ties of the glycylcycline GAR-936 against gram-positive bacteria. Antimicrob Agents Chemother 44: 2225-2229.

Brandenburg AH, van Belkum A, van Pelt C, Bruining HA, Mouton JW, Verbrugh HA 1996. Patient-to-patient spread of a single strain of Corynebacterium striatum causing infections in a surgical intensive care unit. J Clin Microbiol 34: 2089-2094.

Camello TCF, Mattos-Guaraldi AL, Formiga LCD, Marques EA 2003. Nondiphtherial Corynebacterium species isolated from clinical specimens of patients in a University Hospital, Rio de Janeiro, Brazil. Brazilian J Microbiol 34: 39-44.

Camello TCF, Souza MC, Martins CAS, Damasco PV, Marques EA, Pimenta FP, Pereira GA, Hirata Jr R, Mattos-Guaraldi AL 2009. Corynebacterium pseudodiphtheriticum isolated from relevant clinical sites of infection: a human pathogen overlooked in emerging countries. Lett App Microbiol 48: 458-464.

CDC - Center for Disease Control and Prevention 1992. 1993 revised classification system for HIV infection and expanded surveillance case definition for AIDS among adolescents and adults. Morb Mortal Wkly Rep Recomm Rep 41: 1-19.

Chiu YL, Wu VC, Wun KD, Hsueh PR 2005. Recurrent peritonitis caused by Corynebacterium amycolatum in a patient undergoing continuous ambulatory peritoneal dialysis. Clin Nephrol 63: $241-242$.

Clarke R, Qamruddin A, Taylor M, Panigrahi H 1999. Septic arthritis caused by Corynebacterium amycolatum following vascular graft sepsis. J Infect 38: 126-127.

CLSI - Clinical and Laboratory Standards Institute 2007. Methods for antimicrobial dilution and disk susceptibility testing of infrequently isolated or fastidious bacteria. Approved Standard Document M45-A, CLSI, Wayne, p. 4-6.

Daniels C, Schoors D, Van Camp G 2003. Native valve endocarditis with aorta-to-left atrial fistula due to Corynebacterium amycolatum. Eur J Echocardiogr 4: 68-70.

de Miguel I, Rodriguez E, Martin AM 1999. Corynebacterium amycolatum: sepsis in hematologic patients. Enferm Infecc Microbiol Clin 17: 340-341.

Dobbs TE, Patel M, Waites KB, Moser SA, Stamm AM, Hoesley CJ 2006. Nosocomial spread of Enterococcus faecium resistant to vancomycin and linezolid in a tertiary care medical center. J Clin Microbiol 44: 3368-3370.

Esteban J, Nieto E, Calvo R, Fernandez-Robals R, Valero-Guillen PL, Soriano F 1999. Microbiological characterization and clinical significance of Corynebacterium amycolatum strains. Eur J Clin Microbiol Infect Dis 18: 518-521.

Freney J, Duperron MT, Courtier C, Hansen W, Allard F, Boeufgras JM, Monget D, Fleurette J 1991. Evaluation of API Coryne in comparison with conventional methods for identifying coryneform bacteria. J Clin Microbiol 29: 38-41.

Funke G, Bernard KA 2003. Coryneform gram-positive rods. In: PR Murray, EJ Barron, JH Jorgensen, MA Pfaller, RH Yolken, Manual of Clinical Microbiology, 8th ed., ASM Press Washington DC, p. 472-501.

Funke G, Punter V, von Graevenitz A 1996. Antimicrobial susceptibility patterns of some recently established coryneform bacteria. Antimicrob Agents Chemother 40: 2874-2878.

Funke G, von Graevenitz A, Clarridge JE, Bernard KA 1997. Clinical microbiology of coryneform bacteria. Clin Microbiol Rev 10: $125-159$.

Furtado GH, Mendes RE, Pignatari AC, Wey SB, Medeiros EA 2006. Risk factors for vancomycin-resistant Enterococcus faecalis bacteremia in hospitalised patients: an analysis of two case-control studies. Am J Infect Control 34: 447-451.
Garner IS, Iarvis WR, Emeri TG, Horan TC, Hughes IM 1988. CDC definitions for nosocomial infections. Am J Infect Contr 16: $128-140$.

Gilbert DN, Moellering RC, Eliopoulos GM, Sande MA 2006. Comparison of antimicrobial spectra. In DN Gilbert et al. The Sanford guide to antimicrobial therapy, 36th ed., Antimicrobial Therapy Inc, Hyde Park, p. 53-55.

Hughes WT, Flynn PM, Williams BG 1996. Nosocomial infection in patients with neoplastic diseases. In: CG Mayall, Hospital epidemiology and infection control, Williams \& Wilkins, Baltimore, p. 618-631.

Knox KL, Holmes AH 2002. Nosocomial endocarditis caused by Corynebacterium amycolatum and other nondiphtheriae corynebacteria. Emerg Infect Dis 8: 97-99.

Lagrou K, Verhaegen J, Janssens M, Wauters G, Verbist L 1998. Prospective study of catalase-positive coryneform organisms in clinical specimens: identification, clinical relevance and antibiotic susceptibility. Diagn Microbiol Infect Dis 30: 7-15.

Maki DG, Weise CE, Sarafin HW 1977. A semiquantitative culture method for identifying intravenous-catheter-related infection. N Engl J Med 296: 1305-1309.

Martinez-Martinez L, Ortega MC, Suarez AI 1995. Comparison of Etest with broth microdilution and disk diffusion for susceptibility testing of coryneform bacteria. J Clin Microbiol 33: 1318-1321.

Meyer DK, Reboli AC 2005. Others Corynebacteria and Rhodococcus. In: GL Mandell, R Dolin, JE Bennet, Principles and practice of infectious diseases, Churchill-Livingstone, New York, p. 2465-2478.

Osterwalder B, Frei R, Gratwohl A, Reber H, Speck B 1986. Antibiotic-resistant Corynebacteria - a new problem of infection in immunosuppressed patients. Schweiz Med Wochenschr 116: $880-884$.

Oteo J, Aracil B, Alós JI, Gómez-Garcés JL 2001. Bacteriemias significativas por Corynebacterium amycolatum: un patógeno emergente. Enferm Infec Microbiol Clin 19: 103-106.

Otsuka Y, Ohkusu K, Kawamura Y, Baba S, Ezaki T, Kimura S 2006. Emergence of multidrug-resistant Corynebacterium striatum as a nosocomial pathogen in long-term hospitalized patients with underlying diseases. Diag Microbiol Infect Dis 54: 109-114.

Rozdzinski E, Kern W, Schmeiser T, Kurrle E 1991. Corynebacterium jeikeium bacteraemia at a tertiary care center. Infection 19: 201-204.

Schiff H, Mücke C, Lang SM 2004. Exit-site infections by non-diphtheria corynebacteria in CAPD. Perit Dial Int 24: 454-459.

Schoen C, Unziker C, Stuhler G, Elias J, Einsele H, Grigoleit GU, Abele-Horn M, Mielke S 2009. Life-threatening infection caused by daptomycin-resistant Corynebacterium jeikeium in a neutropenic patient. J Clin Microbiol 47: 2328-2331.

Sierra JM, Martinez-Martinez L, Vazquez F, Giralt E, Vila J 2005. Relationship between mutations in the gyrA gene and quinolone resistance in clinical isolates of Corynebacterium striatum and Corynebacterium amycolatum. Antimicrob Agents Chemother 49: 1714-1719.

Thomson Jr RB 2007. Specimen collection, transport and processing: bacteriology. In: PR Murray, EJ Baron, JH Jorgensen, ML Landry, MA Pfaller, Manual of clinical microbiology, ASM Press, Washington DC, p. 485-514.

van der Lelie H, Leverstein-Van Hall M, Mertens M, van Zaanen HC, van Oers RH, Thomas BL, von dem Borne AE, Kuijper EJ 1995. Corynebacterium CDC group JK (Corynebacterium jeikeium) sepsis in haematological patients: a report of three cases and a systematic literature review. Scand J Infect Dis 27: 581-584. 
Vaneechoutte M, De Bleser D, Claeys G, Verschraegen G, De Baere T, Hommez J, Devriese LA, Riegel P 1998. Cardioverter-lead electrode infection due to Corynebacterium amycolatum. Clin Infect Dis 27: 1553-1554.

von Graevenitz A, Frommelt L, Punter-Streit V, Funke G 1998. Diversity of coryneforms found in infections following prosthetic joint insertion and open fractures. Infection 26: 36-38.

Weiss K, Laverdière M, Rivest R 1996. Comparison of antimicrobial susceptibilities of Corynebacterium species by broth microdilution and disk diffusion methods. Antimicrob Agents Chemother 40: $930-933$

Zalas P, Mikucka A, Gospodarek E 2004. Antibiotic sensitivity of Corynebacterium amycolatum. Med Dosw Mikrobiol 56: 327-334.

Zinkernagel AS, von Graevenitz A, Funke G 1996. Heterogeneity within Corynebacterium minutissimum strains is explained by misidentified Corynebacterium amycolatum strains. Am J Clin Pathol 106: 378-383. 